\title{
Teaching Sophomore-Level Engineering Design in 'Paradise'
}

\author{
Heidi G. Loshbaugh, Ph.D. \\ Design EPICS Division \\ Colorado School of Mines
}

\begin{abstract}
Delivering sophomore-level engineering design on a Caribbean island provides the foundation for a vastly broadened student perspective on the field of engineering and how it changes lives. In addition, it offers the basis for life-long learning about one's role in the world at large.
\end{abstract}

The Colorado School of Mines EPICS program, a two-semester, interdisciplinary engineeringdesign course, delivers a 3-week, optional course in St. Kitts, West Indies. Student teams work directly with the national government on solving environmental problems. In May 2000 and 2001, students mapped boundaries of a wilderness preserve, addressed life-threatening problems with soil erosion, discovered the source of toxins responsible for destroying a unique mangrove habitat, and provided wastewater treatment for the national prison and hospital.

In so doing, students from a technologically advanced campus have solved problems in feasible and affordable ways. They also have found themselves responsible for managing their time, efforts, and behavior in a setting that encourages relaxation and ease more than productivity and hours on the job. Furthermore, students have had direct contact with local residents and gained appreciation for some of the range of cultural differences that exist in the English-speaking world.

This course practices collaboration between an American university of engineering and technology and a developing nation, teaches the importance of cultural sensitivity for engineers in designing solutions to problems, and illustrates the close relationship between human action and the potentially negative effects on the environment.

\section{program and course considerations}

In May 2000 and 2001, I traveled with undergraduates from the Colorado School of Mines (CSM), in Golden, Colorado, to St. Kitts, West Indies, to conduct summer field sessions in sophomore-level engineering design. In 2000, a team of 3 faculty members traveled with 26 students; in 2001, I was the sole faculty member with 13 students. My program, EPICS, or Engineering Practices Introductory Course Sequence, is a two-semester course required of all students at CSM. The first-year course is EPICS I, the sophomore year, EPICS II. 
Our courses are interdisciplinary and project based. Students work in teams of 4-6 to solve cliented technical problems, improve communication skills, and develop proficiency in the process of engineering design. Visualizing, creativity, data analysis, cooperative learning, and providing sound logical and technical support for solutions are chief components of this program.

In St. Kitts, the client for all projects is the Ministry of Health and the Environment. Over the last two years, EPICS II students have mapped boundaries of a wilderness preserve, addressed life-threatening problems with soil erosion, discovered the source of toxins responsible for destroying a unique mangrove habitat, and provided wastewater treatment for the national prison

and hospital. Students have worked closely with employees in the Ministry of the Environment, as well as community members on the island. They also receive classroom instruction, meet regularly with faculty members - known in the program as mentors - spend long hours in the field, and work closely with teammates to develop a solution to the team's project.

Students make 3 presentations to their clients; the final presentation is open to the public. The presentations routinely take up to 1 hour, both for delivery of information and for exchanges with the client. Teams are also responsible for 3 technical reports: a project plan developing the strategy the students intend to follow to solve their assigned problem; a component breakdown in which individual students discuss their particular area of expertise within the larger project; and a final report, detailing the team's analysis, actions, and recommendations to the client.

Students are housed in a business-class hotel, the Ocean Terrace Inn, or OTI, about 1 mile outside the capital city of Basseterre. Most student rooms have kitchenettes and 2 or 3 students room together. The OTI has conference rooms for class sessions and student meetings or presentations, although, frequently, meetings take place in student rooms, in a faculty-member's suite, or outside, as temperatures, even in the late evening, rarely fall below 75 degrees Fahrenheit. The Ministry of Environment provides transportation much of the time, although students have also relied on the hotel shuttle, public busses, and taxis for distant sites. Because of the OTI's proximity to government offices, restaurants, and clubs, often, students simply walk.

\section{cultural factors: CSM}

Colorado School of Mines in Golden, Colorado, is a public university specializing in teaching engineering and technology. As of Fall 2001, the population was 3350 students, 25.82 percent of which was female, 11.2 percent, minorities, 12.45 percent, international students. By state law, 75 percent of students admitted to CSM must come from Colorado. Nearly 200 study abroad, 50-60 in short courses, the remainder in semester-long or year-abroad programs.

Golden works hard to keep its integrity as a town, rather than a suburb of nearby Denver, and is proud of its heritage as a pioneer community in the state. The small campus in a small western town has a distinct "middle-America" feel to it. Students are from the top 10 percent of their graduating high school classes; they tend to be hard working and high achieving. In addition, these students tend to be attracted to practical applications of their studies; they want to see how their work relates to a larger-world picture. 
The campus community is heavily reliant on technology; students, faculty, and staff have widespread access to cutting-edge computing systems and make use of them as a matter of course in conducting classroom business. Students depend on the Internet to gather information 24 hours a day, 7 days a week, and the campus library and computing centers offer extended hours for students to work on projects, particularly during peak times, including mid-term exams and finals. Laptops, Palm Pilots, and the latest pocket HP are routine gear anywhere on campus.

\section{cultural factors: St. Kitts}

The 2-island Caribbean nation of St. Kitts and Nevis is a former British colony and was exploited heavily for sugar production, although this industry is being phased out. Tourism is now a central feature of the economy. From the Minister of Tourism to locals in the grocery story, Kittians refer to their island as "paradise," and they believe it. English is the official language.

This is not a 24/7 business world. The local office-supply store routinely is back-ordered up to 3 weeks on printer cartridges. Appointment times are fluid; students have waited up to 1.5 hours for a scheduled meeting or pick up only to receive a call to inform them that the meeting or site visit will have to be rescheduled. Most shops, including grocers, close between 5:30-6 p.m. weekdays, in early afternoon on Saturdays, and are closed on Sundays. Popular restaurants, too, have circumscribed hours by United States' standards; a fish house at the OTI is open from 7-10 p.m., daily. The principal dance club, Mangoes, opens at 9 p.m. and closes around 4 a.m.; there is no last call.

Alcohol is cheap and easily available with no age restrictions; a bottle of the locally brewed Carib sells at the grocer for about \$.75. The OTI hosts a Tuesday-night, Manager's Rum Punch Party from 7-8 p.m. with an open bar and minimal appetizers; all guests are invited. Illicit drugs are widely available, as well. Students and one faculty member have been approached with offers of drugs for sale.

Casual sex and multiple partners are common; as with many islands in the Caribbean, St. Kitts and Nevis have serious and growing problems with HIV/AIDS infections. Because residents of St. Kitts and Nevis are predominately of African descent and because the students who traveled with me in the last two years are exclusively of European-American ancestry, the CSM students experience being a minority in a majority culture different from their own.

Loud music, political campaign speeches, and impromptu sermons blare from speakers in the Basseterre Harbor or private cars and boom boxes from early morning until midnight. Although at resorts and in housing developments, various states of casual clothing prevail, in businesses and governmental offices, workers and visitors dress much more formally than one often sees in the United States. Professional women wear tailored linen or silk dresses and suits; men wear suits or tailored pants and shirts. Tourists and college students stand out in business settings with their tee-shirts, flip-flops, and baggy shorts. 


\section{opportunities for education}

While on campus, EPICS II students routinely have contact with their clients 3 or 4 times in a 16 -week semester. If the project is locally based, students go into the field to examine the situation first hand. Contact with the client and seeing the problem personally help to get students involved in their work; nevertheless, some students still insist on seeing EPICS as simply a classroom exercise. In St. Kitts, students have immediate and often daily contact with their clients and see that local residents have immediate and daily contact with the problems in need of redress; as a result, students tend to become heavily invested in the outcome of their recommendations. This world is as real as it gets.

Because St. Kitts operates on different cultural expectations and because our students do not have the highly structured, familiar environment of the CSM campus and Golden, Colorado, distractions, time management, and personal responsibility take on entirely new meanings. Because resources and technology are not as easily available, students learn the meaning of their own economic and technological privilege.

Given the disparities between life in Golden and in St. Kitts, this field session allows students to learn about themselves, as well as their values, developing professionalism, role in the larger world, and the potential for engineering to affect peoples' lives directly.

\section{projects: ghaut soil erosion}

In May 2000 and 2001, students mapped boundaries of a wilderness preserve, addressed lifethreatening problems with soil erosion, discovered the source of toxins responsible for destroying a unique mangrove habitat, and provided wastewater treatment for the national prison and hospital. I will discuss the soil-erosion and wastewater-treatment projects in greater detail.

St. Kitts is a volcanic island with deep ravines for run-off; locally, the ravines are known as "ghauts." As long as the ghauts are heavily vegetated, the friable soil remains stable. However, agricultural clear-cutting, residential development, road building, and poor solid-waste management practices have caused soil-erosion problems of increasingly serious magnitude. In heavy storms, whether seasonal rains or periodic hurricanes, the flow of water, eroded soil, and pollution has become so great that automobiles, livestock, and human beings have been carried away. Houses built near the ghauts have been made uninhabitable and roadways impassable because the earth beneath has washed away. Basseterre, has been inundated by water and several feet of mud, and the harbor filled with 8-10 ft of sludge.

Over the last two summers, 3 EPICS teams have worked on soil-erosion problems in the ghauts, and one team's recommendations have become the foundation for a governmental study into addressing the problem. College Street Ghaut starts high in the volcanic hills above Basseterre and winds its way down through fields of sugar cane, new housing developments, and some new-growth rainforest. Scattered alongside the walls of the ghaut are older houses, some of which are increasingly in peril, given the erosion taking place. The ghaut ranges from broad and shallow-about $8 \mathrm{ft}$ deep and $30 \mathrm{ft}$ wide - to deep and precipitous-about $18 \mathrm{ft}$ deep and $10 \mathrm{ft}$ wide - as it meanders toward the center of Basseterre and the harbor. 
At some points, the ghaut is lined with banana and mango trees, their thick roots exposed 8 or 10 $\mathrm{ft}$ because the soil has washed away. In some, particularly deep recesses, people have set up housekeeping in the caves formed by the erosion yet sheltered by the roots of the trees. At other points, the walls are bare and subject to decay, even from the breath of passersby blowing on the friable soil. Sugar cane develops long matted root networks and actually serves to prevent erosion; the dismantling of the sugar industry is destroying the cane fields and the role they play in slowing erosion.

Most noteworthy is the condition of the ghaut along and below the older residential areas. St. Kitts has no regular garbage collection service, a failing landfill that is leaching toxic waste into nearby marine habitats, and a resistance to raising taxes to pay for improvements for the nation's waste disposal system. Residents along College Street Ghaut "address" this problem by tossing garbage out their back doors and into the ghaut.

The walls and floor of the ravine are lined with household waste-tin cans, grocery bags, disposable diapers - as well as discarded durable goods — steam irons, kitchen ranges, washing machines, and porcelain toilets. In a rainstorm, this debris diverts water from its natural channel and forces it into the walls of the ghaut, which then are further eroded. If rainfall is heavy enough, the discards are carried downstream with the flood. The soil, water, and garbage then wash into the streets of Basseterre and finally into the harbor. In 1999, the harbor became a garbage stew during a hurricane, and the floor of the harbor required dredging several times in the past decade to keep it at a navigable $25 \mathrm{ft}$.

To address and redress the impact of soil erosion on this and other ghauts, EPICS teams have employed various strategies that truly demonstrate the interdisciplinary nature of engineering design as taught at CSM. They have spent hours in the field conducting on-site inspections, including hiking several miles up the ghaut with a local naturalist, interviewed the director of the sugar production facility, who has extensive experience with remediation and prevention of soil erosion, researched reports developed by a consortium of West Indies scientists, as well as investigated local weather patterns and coastal features.

Recommendations included making and installing gabion baskets, coated-wire mesh shells filled with rock, which would be located along ghaut walls at vulnerable points and then backfilled with soil; planting a network of dense and various vegetation, including local grasses, vines, and trees to stabilize the soil at shallow, intermediate, and deep levels; restructuring the channel to follow natural contours; and creating terraced settling ponds for sediment. The work EPICS students did on College Street Ghaut has been recommended by the Director of the Ministry of the Environment as the foundation for work a government and community task force will use to make improvements along the ravine.

\section{projects: Her Majesty's Prison}

In May 2001, a team of students was asked to address wastewater treatment problems at the national prison. The prison had had overflow wastewater and a strong stench of hydrogen sulfide emanating from its front portal for more than 30 years. The problem was so notorious that protest songs across the Caribbean make reference to the raw sewage at Her Majesty's 
Prison in Basseterre. Next door to the prison is the city's police station. For wastewater disposal, the two facilities rely on a series of septic tanks emptied on a regular basis because the city lacks a central sewage treatment plant.

Our client for the project, an environmental officer for the Ministry of the Environment, has a background in chemistry and was on a mission to solve the problem at the prison. The 4 students, 2 men and 2 women, became an instrument in his mission. He suspected that overflow from the police station was the actual culprit, but a careful search of the prison yard and police yard yielded no access to the police station's holding tank, only to those of the prison. After several hours of scouring the prison yard, he sent the team home with notebooks on water treatment processes and the instruction to be at the prison early the next morning. Under the direction of their client, the students developed a 3-chamber water treatment system to filter and aerate, chlorinate, and deodorize the gray water before it was released onto the public street.

When the team arrived at the prison the second morning, their client had a team of prisoners assembled, ready to dig. Although murderers are not allowed out to perform community service, thieves, sex offenders, tax evaders, and other low-risk prisoners are routinely used for free labor as a part of their debts to Kittian society. In the prison yard, using pickaxes and shovels, the prisoners broke through a layer of asphalt and concrete, then dug a trench. Dennis, a mason, became the foreman of the crew and provided good support and advice for the students. Rather to their dismay, he finished his sentence for failure to pay taxes 1 week into their project and went home to his family, leaving them without the technical support they had come to depend on.

The prisoners had full access not only to ground-breaking tools, but also to circular and chain saws, power drills, hammers, nails, and $8 \mathrm{ft}$ lengths of rebar and $2 \mathrm{X} 4$ 's. Although the tools had to be stored each evening, during the day, much or all of this construction equipment was lying about the prison yard. The students, none of whom had any construction experience, would wave at a piece of plywood or rebar, say, "Cut that," or point at the trench and say, "Dig here," and one of the prisoners, dressed in a chambray shirt, denim knee-length shorts, and rubber flipflops, would do so.

The students developed good working relationships not only with the prisoners but also with the various guards, wardens, and the prison commissioner himself. When a television crew from the local nightly news showed up to film the work in progress, the guards turned them away. Two students were leaving for lunch as the crew retreated from the prison entrance. Among other things, they were turned away because the prison commissioner had banned media in the institution following a particularly negative undercover report earlier in the year. The EPICS students told the guards, "They're with us," and, with no further argument, ushered the reporter and camera operator in for an interview and personal tour of the work site; the clip aired on the evening's national news.

After 3 weeks on the job, the students ended up with an operational water-treatment system. They had included a shut-off valve to control inflow and were able to prove that the police station was indeed responsible for the overflow, which meant that the police commissioner had to pay for the materials and take the rap for the decades-old problem. The labor, of course, was 
free. When the team delivered their final report to the prison commissioner, he praised their work, thanked them profusely, and told them that even if the problem were not permanently solved, he was enormously grateful for their efforts.

\section{reactions and lessons learned}

Students have responded in admirable and creative ways to the cultural differences and challenges to productivity that these differences engender. Alcohol consumption is a significant issue because liquor is so readily available and so cheap. The program has been explicit that students must be punctual, functional, and prepared for all school-related activities and have given them guidelines for courteous behavior while in a foreign country.

One interesting aspect of the students' learning curve is observing their behavior upon arrival and just prior to departure. At the first hotel party, students often drink to excess. After having to spend long days in the field in 90 degree weather and 95 percent humidity, student interest in excessive alcohol consumption wanes visibly. At farewell receptions on the last nights of our stay in both 2000 and 2001, fruit punch was the beverage of choice, despite the availability of other options. Their professional behavior matures in response to the demands of their work and environment, not because of rules and regulations.

Undeniably, students sign up for the trip because the prospect of spending 3 weeks on a Caribbean island and getting credit for it sounds like a great deal. An article in the New York Times Education Life of April 8, 2001, notes that this is a typical student anticipation of studyabroad experiences. "Even before attending freshman orientation, many students have already decided to study abroad....Students may not know where they want to go, or what they want to study, but they know they don't want to miss 'the experience of a lifetime"' (Altschuler, 2001, 17). When I tell people about the EPICS overseas program, the inevitable re sponse is a nudgenudge-wink-wink suggestion that this field session is a great scam.

One student who has visited the region with his family a number of times as a tourist and went with EPICS in 2000 because "it sounded like a good time" would like to return with his engineering degree to work with the Kittian government on environmental remediation projects. He had never seen the unkempt, impoverished side of the Caribbean and wants to work to improve the lives of people who do not share the personal privilege of his upbringing.

He and four other students from that trip planned to return to St. Kitts with their families in December 2001, to build housing they had designed for local residents. The residents they targeted were those living behind the screen of mango and banana roots in the caves of College Street Ghaut. These students' parents pulled the plug on travel and funding to return to St. Kitts following September 11.

Nevertheless, student reactions have varied. One student in May 2000 told me that he would be very happy to return to the United States because the poverty and ubiquitous garbage were getting to him. A woman in 2001 was dismayed by the "sexually predatory behavior" of the local men; another woman on that trip was struck by the multiple partners Kittian men have children with and was concerned with the welfare of those children. 
The misperception of the Caribbean as one big resort beach is a major obstacle residents of the West Indies struggle with in their efforts to address serious and life-threatening problems (Gilmore, 2000). Awakening to this misperception has been a powerful learning experience for our students. By experiencing at first hand the economic, cultural, and environmental challenges Kittians face in their daily lives, CSM students have come to see and appreciate their privilege, as well as learning to value the richness of a different way of life.

\section{implications for engineering education}

Nationwide, fewer than "3 percent of U.S. undergraduates study abroad" (Marcum, 2001, B7). John A. Marcum, director of the University of California Education Abroad Program, has found that engineering and physical sciences are poorly represented in his international education program and suggests that pre-major courses taken during the sophomore year might be a helpful way to encourage "underrepresented categories [of] science [and] engineering" to participate in study abroad programs." Marcum also suggests that "short-term programming" may be a useful tool in disciplines with "inflexible programming" (Marcum, 2001, B7).

The success of our program in its first 2 years indicates that short courses conducted prior to students' entry into their majors is a beneficial way for them to gain international experience without disrupting their progress toward degree completion.

A great deal of the EPICS program is based in experiential learning practice; students learn the design process by doing it. This assumes that students seek immediate applicability of the lessons learned. EPICS in St. Kitts demonstrates the immediate need for practical engineering solutions to problems faced in developing countries. Students come to recognize that their design decisions matter, that engineering is a vital, life-changing profession, and that achieving a balance between work and play is necessary to any healthy individual. Thus, in our overseas short course, EPICS addresses fundamentals of engineering design and teamwork, life-long learning, and heightened sensitivity to the world community and the environment it lives in.

\section{Bibliography}

Altschuler, G.C. (April 8, 2001). La Dolce Semester: Studying Abroad Is Most Student's Favorite College Experience. But Not Necessarily for the Right Reasons. New York Times Education Life, 17.

Gilmore, J. (2000). Faces of the Caribbean. London: Latin America Bureau, Ltd.

Marcum, J.A. (May 18, 2001). Eliminate the Roadblocks. Chronicle of Higher Education, B7.

\section{Biographical Information}

Heidi G. Loshbaugh, Ph.D., is currently in her fourth year in the engineering design program EPICS at the Colorado School of Mines. In addition to teaching, she has been responsible for new materials and course development, including EPICS II in St. Kitts, and Leadership EPICS II. She has also worked extensively on faculty training to facilitate improved methods and materials for teaching communications, teamwork, and design. 